\title{
RECICLAGEM AGRÍCOLA DE BIOSSÓLIDOS: ASPECTOS AMBIENTAIS E ACEITAÇÃO PÚBLICA
}

\author{
Renata Delfino Pereira, Edilene M. Murashita Takenaka, Antonio Fluminhan Jr. \\ Programa de Pós-Graduação em Meio Ambiente e Desenvolvimento Regional da Universidade do Oeste Paulista - \\ UNOESTE, Presidente Prudente. \\ Correspondência para Antonio Fluminhan Junior - fluminhan@unoeste.br
}

\section{RESUMO}

A população humana, enquanto parte do ecossistema terrestre, possui comportamentos que agem em sentido contrário à manutenção do equilíbrio do meio ambiente. Os principais fatores que alteram este equilíbrio estão relacionados ao consumo de recursos e energia e à produção de resíduos. As águas residuais domésticas são, basicamente, compostas por águas de banho e lavagem, urina, fezes, restos de alimentos, sabões e detergentes e o seu tratamento, além de ser uma questão de saúde pública, é uma medida de preservação ambiental. O lodo é produzido nas Estações de Tratamento de Esgoto em quantidades significativas e sua destinação final é um sério problema ambiental. Quanto ao gerenciamento deste resíduo, pode-se optar pelo descarte controlado ou a utilização para outras atividades humanas. As alterações benéficas nas características físicas, químicas e biológicas do solo, o aumento da produtividade agrícola e os consequentes benefícios socioeconômicos tornam a reciclagem agrícola a prática mais adequada dentre as formas de disposição final dos lodos residuais. Porém, a falta de aceitação pública da utilização de biossólidos, tanto por parte dos produtores quanto pelos consumidores finais, pode ser um fator de inviabilidade da atividade. O presente trabalho tem como objetivo realizar uma reflexão sobre a aceitação dos alimentos cultivados em solos tratados com biossólidos por parte da sociedade e possíveis propostas de pesquisas futuras sobre a reciclagem agrícola.

Palavras-chave: Águas residuais. Biossólido. Reciclagem agrícola. Sociedade.

\begin{abstract}
Human populations, as part of the Earth's ecosystem, have behaviors that act in the opposite direction to maintain the environmental balance. The main factors that alter this balance are related to the consumption of resources and energy and waste. Domestic wastewater is primarily composed of water bath and washing, urine, feces, uneaten food, soaps and detergents and its treatment, besides being a public health issue, is a measure of environmental preservation. The sludge is generated in Sewage Treatment Plants in significant quantities and its disposal is a serious environmental problem. Regarding the management of this waste, you can opt for the controlled disposal or use. The beneficial changes in physical, chemical and biological soil properties, increased agricultural productivity and the resulting socio-economic benefits make the agricultural recycling practice amongst the most appropriate forms of final disposal of waste sludge. However, the lack of public acceptance of biosolids use, both by producers and final consumers, it may be a factor of viability of the activity. The present work aims to develop a reflection on the acceptance of food grown in soils treated with biosolids by society and possible proposals for future research on its agricultural recycling.
\end{abstract}

Keywords: Wastewater. Biosolid. Agricultural recycling. Society. 


\section{INTRODUÇÃO}

A população humana, enquanto parte do ecossistema terrestre, possui comportamentos que agem em sentido contrário à manutenção do equilíbrio do meio ambiente. Os principais fatores que alteram este equilíbrio estão relacionados ao consumo de recursos e energia e à produção de resíduos.

A problemática ambiental atual pode ser atribuída a duas situações: o crescimento demográfico e a produção industrial, ambos fatores de pressão sobre os recursos naturais. Portilho (2005) ressalta que o meio ambiente não está relacionado apenas à questão de como os recursos naturais são utilizados (padrão de consumo) mas também à preocupação com quanto destes recursos são utilizados (nível de consumo).

A relação do ser humano com a água tem sido objeto de importantes discussões atuais, no que diz respeito à redução da disponibilidade dos recursos naturais. 0 aumento da demanda de água potável por consequência do crescimento populacional, e seu desenvolvimento tecnológico, agrava o descompasso com a oferta. Maior demanda de água implica aumento em uso e descarte sob a forma de águas residuais, que retornam aos recursos hídricos. Tais recursos possuem capacidade de autodepuração e degradação dos poluentes, porém esta capacidade é limitada e incompatível com a quantidade de efluente gerada pelos centros urbanos (SANTOS, 2003).

O saneamento básico abrange um conjunto de ações estabelecidas para manter ou alterar o ambiente, controlando a ocorrência de doenças a fim de promover saúde e bem-estar para a população. As práticas de saneamento incorporam políticas de abastecimento de água, esgotamento sanitário, sistemas de drenagem, coleta e tratamento dos resíduos sólidos, refletindo diretamente sobre a qualidade de vida determinada historicamente através de políticas públicas envolvendo aspectos socioeconômicos e culturais e mantendo uma interface com as políticas de saúde, meio ambiente e desenvolvimento urbano (SOUZA, 2002).

Nas 81 maiores cidades do Brasil com mais de 300 mil habitantes, são produzidos diariamente 9,3 bilhões de litros de efluentes domésticos (OMS, 2010), que são tratados e, em parte, transformados em lodo. Entre as diversas destinações, como incineração, disposição em aterros sanitários, landfarming, a reciclagem agrícola do biossólido apresenta-se como uma alternativa para redução da pressão sobre a exploração dos recursos naturais e como forma de evitar destinações finais que envolvam custos mais elevados e com maior 
impacto no ambiente e na população.

O presente trabalho pretende realizar levantamentos bibliográficos sobre a questão do tratamento de efluentes urbanos no Brasil, a geração de lodo nas Estações de Tratamento de Esgotos (ETE) e a alternativa de reciclagem agrícola deste resíduos, a fim de embasar teoricamente uma reflexão sobre a aceitação dos alimentos cultivados em solos tratados com biossólidos por parte da sociedade.

\section{OS EFLUENTES DOMÉSTICOS}

As águas residuais caracterizam-se pelos despejos provenientes dos diversos usos da água, como o doméstico, comercial, industrial, agrícola, etc. O efluente doméstico é basicamente composto por águas de banho e lavagem, urina, fezes, restos de alimentos, sabões e detergentes, apesar de sua composição qualitativa e quantitativa variar em função dos hábitos e condições socioeconômica das populações, da existência de ligações clandestinas de águas pluviais na rede coletora de esgoto, do estado de conservação desta rede coletora, do clima local, entre outros (BRAGA et al. 2005).

Os efluentes domésticos contêm, ainda, organismos como bactérias, vírus, protozoários e helmintos, que são despejados juntamente com as excretas humanas. Alguns microrganismos possuem papel importante no tratamento das águas residuais, uma vez que decompõem a matéria orgânica complexa em compostos mais simples e estáveis. Em contrapartida, a presença de organismos patogênicos e a contaminação da água, do solo e dos alimentos torna-se um problema de saúde pública.

A Lei $11.445 / 07$, em seu art.3으, define Saneamento Básico como sendo o conjunto de serviços, infraestrutura e instalações operacionais de abastecimento de água potável, esgotamento sanitário, limpeza urbana e manejo de resíduos sólidos e drenagem e manejo de águas pluviais urbanas.

A oferta de saneamento básico é fundamental para a garantia da qualidade de vida, pois sua ausência contribui para a poluição dos recursos hídricos e consequente prejuízo à saúde da população, aumentando, principalmente, o número de casos de mortalidade infantil. Segundo a Pesquisa Nacional de Saneamento (PNSB 2008), somente $55,2 \%$ dos municípios do Brasil possuem serviço de rede coletora e apenas $28,5 \%$ dos municípios realizam o tratamento deste efluente coletado.

\section{TRATAMENTO DE EFLUENTES URBANOS}

O tratamento dos efluentes urbanos, além de ser uma questão de saúde pública, é uma medida de preservação ambiental e consiste, genericamente, num conjunto de processos físicos, químicos e biológicos que 
resultam na remoção da matéria orgânica e dos sólidos sedimentáveis. O resultado destes processos é a produção de um resíduo sólido em quantidade e composições variáveis em função das características do efluente e do tratamento adotado (BRAGA et al., 2005).

O tratamento preliminar objetiva apenas a remoção dos sólidos grosseiros e o tratamento primário visa a remoção dos sólidos sedimentáveis e, em decorrência, parte da matéria orgânica. Em ambos os tratamentos predominam os mecanismos físicos de remoção de poluentes. Já no tratamento secundário, no qual predominam mecanismos biológicos, o objetivo é principalmente a remoção de matéria orgânica e eventualmente nutrientes, como nitrogênio e fósforo. O tratamento terciário, etapa rara em Estações de Tratamento de países em desenvolvimento, objetiva a remoção de poluentes específicos, tóxicos ou não biodegradáveis, e a remoção complementar de poluentes insuficientemente removidos no tratamento secundário (VON SPERLING, 2005).

\section{GERAÇÃO DE LODO DO TRATAMENTO DE EFLUENTES URBANOS E A SUA UTILIZAÇÃO}

Nos processos biológicos de tratamento, parte da matéria orgânica é absorvida pela biomassa microbiana. Este lodo composto principalmente por sólidos biológicos é denominado biossólido. Para que este termo possa ser adotado é necessário ainda que suas características químicas e biológicas sejam compatíveis com uma utilização produtiva, como a reciclagem agrícola. O termo "biossólido" ressalta os aspectos benéficos de sua utilização em comparação mera disposição final improdutiva por meio de aterros, landfarming, disposição superficial no solo ou incineração (BRAGA et al., 2005).

O lodo é gerado nas Estações de Tratamento de Esgoto em quantidades significativas e sua destinação final é um sério problema ambiental. Quanto ao gerenciamento deste resíduo, pode-se optar pelo descarte controlado ou a utilização. Em termos de descarte, a tendência é a disposição em aterros sanitários. A utilização mais nobre é na melhoria de solos agrícolas, desde que respeitadas as condições ambientais, características dos solos, culturas, etc. Quando isto não é possível, outras alternativas têm sido estudadas, dentre elas, a inertização em tijolos cerâmicos (NUVOLARI, 2002).

Nas últimas décadas, a prática de coleta e tratamento dos efluentes urbanos vem se tornando sistemática no Brasil em virtude da necessidade de adequado gerenciamento da disposição final do lodo gerado. Pelas características do lodo e pelo conhecimento de alguns de seus efeitos benéficos sobre as propriedades do solo, as 
práticas de uso agrícola e florestal apresentam-se como as mais convenientes, pois a presença de matéria orgânica e/ou macro e micronutrientes viabiliza o uso como condicionador do solo e fertilizante (BETTIOL; CAMARGO, 2006) e, ao mesmo tempo, é uma solução do problema da acumulação em alta escala nas ETE. A aplicação de biossólido ao solo, assim como de outros resíduos ricos em matéria orgânica, vem sendo estudada com o objetivo de otimizar a produção de alimentos e minimizar os impactos ambientais (BOEIRA; SOUZA, 2007).

\section{RECICLAGEM AGRÍCOLA DE BIOSSÓLIDO}

Segundo Souza (2002), o uso de biossólidos na agricultura tem sido muito estudado, as pesquisas brasileiras iniciaramse na década de oitenta e já existem avanços em pesquisas nos Estados de São Paulo e Paraná e em Brasília. Os primeiros estudos sobre o tema foram realizados por Bettiol e Carvalho (1982) e em 1998, um grupo de pesquisadores da Escola Superior de Agricultura Luiz de Queiroz/USP iniciou as primeiras pesquisas de campo sobre a aplicação de biossólidos em culturas florestais no Brasil (GUEDES, 2006).

Em pesquisa sobre o efeito da adubação com lodo submetido a diferentes processos de higienização sobre os teores de metais pesados no solo e em grãos de milho e feijão caupi consorciados, Nogueira et al.
(2007) concluíram que não houve influência dos tipos de biossólidos em relação aos teores de metais pesados em grãos de milho e feijão, assim como Rangel et al. (2006) avaliaram que os teores de magnésio, níquel, chumbo e zinco não provocaram toxicidade em folhas e grãos de milho adubados com biossólidos. Nascimento et al. (2004) observaram que a aplicação de lodo em culturas de milho e feijoeiro elevou os teores de matéria orgânica, nitrogênio, fósforo, potássio e sódio, contribuindo para o aumento da produção de matéria seca, e que os teores de metais pesados presentes no lodo não induziram fitotoxicidade nas plantas.

Silva et al. $(1998,2001)$ e Chiba (2005) analisaram os efeitos da aplicação de biossólido na cultura de cana-de-açúcar e concluíram que o mesmo contribui para o aumento da produtividade, pois fornece elementos de importância nutricional para as plantas, e que a presença de metais pesados não causa contaminação do solo ou da matéria-prima produzida. Em culturas de soja, Vieira et al. (2005) e Correa et al. (2008) observaram aumento de produtividade em solos adubados com biossólido. Para a cultura de girassol, houve aumento significativo da produtividade de grãos, de óleo e de matéria seca (LOBO; GRASSI FILHO, 2007).

As alterações benéficas nas
características físicas (formação de


agregados, aumento da resistência à erosão, aumento da capacidade de retenção de água), químicas (retenção de nutrientes) e biológicas (fornecimento de nutrientes para a flora e fauna) do solo, o aumento da produtividade agrícola e os consequentes benefícios socioeconômicos tornam a reciclagem agrícola a prática mais adequada dentre as formas de disposição final dos resíduos de ETE (ANDREOLI et al., 1997), com a importante ressalva de que estes irão atuar como complementares à adubação química, uma vez que a presença de certos nutrientes é relativamente baixa, sendo necessária a adição de compostos químicos para garantir as necessidades nutricionais dos cultivos (OLIVEIRA et al., 1995; SIMONETE et al., 2003; NASCIMENTO et al., 2004).

\section{ACEITAÇÃO PÚBLICA DO USO DE BIOSSÓLIDOS NA AGRICULTURA}

A invenção do termo "biossólidos" foi baseada na compreensão, verificada por pesquisas na área das ciências sociais, de que este termo remete na maioria das pessoas uma resposta menos negativa do que o termo "lodo" (BEECHER et al., 2004).

Guedes (2005) ressalta que a falta de aceitação pública da utilização de biossólidos, tanto por parte dos produtores quanto pelos consumidores finais pode ser um fator de inviabilidade da atividade. O repúdio pelos dejetos humanos, além do aspecto visual e odores desagradáveis, podem prejudicar a aceitação e comercialização de um produto que tenha sido cultivado em solos tratados com biossólidos. A cultura existente no meio rural de que o lodo de esgoto não é adequado para a agricultura demanda campanhas de sensibilização que atendam as individualidades de cada região e população.

Andreoli et al. (1997) destacam que, além da resistência por parte do agricultor, há também a preocupação com a possível desvalorização da propriedade e dos produtos e o receio do uso de biossólidos em função da presença de patógenos e aspectos de saúde ocupacional.

Os principais fatores que afetam a aceitação pública de biossólidos estão relacionados aos problemas de odor nas etapas de processamento e estocagem. Como as regulamentações garantem a qualidade dos biossólidos em relação ao seu conteúdo de metais e ao risco de problemas sanitários, alternativas de secagem, estabilização e de formas de processamento avançado têm apresentado um grande crescimento. Desta forma, um dos principais fatores de sucesso de um programa de reciclagem é o adequado fornecimento de informações sobre os critérios de segurança adotados e a transparência dos resultados do monitoramento ambiental à comunidade envolvida (ANDREOLI et al., 2001). 


\section{ASPECTOS SOCIOECONÔMICOS}

DA UTILIZAÇÃO DE RESÍDUOS

A opção pelo uso agrícola de um resíduo deve ser baseada em critérios técnicos, legais, ambientais e econômicos. Estes últimos são uma importante etapa na avaliação da viabilidade da reciclagem agrícola. Por mais envolvida com a questão da preservação ambiental que uma empresa seja, os custos da disposição dos resíduos devem ser compatíveis com o seu orçamento, bem como a existência de demanda pelo resíduo e de aceitação por parte dos agricultores (PIRES; MATTIAZZO, 2008).

O deslocamento da questão ambiental para a esfera do consumo pode contribuir para ampliar as experiências da vida diária ao aumentar o sentimento de pertencimento na sociedade através da percepção do significado de ações em relação aos efeitos no ambiente (PORTILHO, 2005).

Desta forma, os problemas ambientais constituem um tema propício para a implementação de alternativas diversificadas para o uso de resíduos e de iniciativas de participação social, garantindo o acesso da população à informação, uma vez que, de acordo com Jacobi (2005), a postura de não responsabilidade com o ambiente decorre da desinformação, falta de consciência ambiental e do déficit de práticas participativas.

Diferentes formas de reciclagem do biossólido estão sendo estudadas e sugeridas como alternativas para a redução de emissões atmosféricas poluentes, redução do volume requerido em aterros sanitários e redução de custos, além de constituir uma forma de aproveitamento benéfico de matéria-prima e energia, diminuindo a pressão sobre os recursos naturais e contribuindo para o modelo de desenvolvimento sustentável (SOUZA, 2003).

\section{PERCEPÇÃO PÚBLICA SOBRE A UTILIZAÇÃO DE BIOSSÓLIDOS}

Em pesquisa realizada na região de Londrina - PR, Zapparoli (2000) entrevistou 184 produtores rurais com o objetivo de avaliar seus conhecimentos sobre biossólidos e a aceitação do uso deste resíduo como complemento na adubação do solo. Quando questionados sobre a utilização de biossólidos, os produtores manifestaram a desinformação sobre o assunto, apesar do interesse em conhecer mais sobre o produto pois acreditam que seja ambientalmente correto. Dos $23 \%$ dos produtores que já ouviram falar sobre biossólidos, a maioria afirma ter conhecimentos superficiais obtidos por meio da mídia (jornais, televisão).

A utilização do biossólidos nas propriedades agrícolas está associada ao nível de informação dos produtores acerca do produto, pois os mesmos afirmaram que a decisão de utilização está aliada à 
recomendação de um profissional de agronomia, devido à deficiência de potássio, cálcio, magnésio neste tipo de resíduo e também à viabilidade econômica do uso agrícola.

$\mathrm{Na}$ opinião dos produtores rurais, as implicações do uso agrícola de adubo complementar produzido com biossólido estão associadas à embalagem, transporte e difícil manuseio do produto, além da preocupação com a contaminação ambiental causada pela possível presença de metais pesados e agente patogênicos.

A gestão dos biossólidos é percebida pela população de formas diferentes. A reciclagem agrícola é uma forma de aproximar o conhecimento deste produto das pessoas, o que resulta na sensibilização destas pessoas e na avaliação sobre o risco para a saúde humana ou para o ambiente (BEECHER et al., 2005). Os cientistas sociais observaram que a percepção de risco é única para cada indivíduo e está intimamente relacionada a valores, educação, experiências e envolvimento com as consequências de tais risco (SLOVIC, 1999).

Segundo Lima e Portilho (2001), a perda de contato com a natureza e de compreensão de sua transformação produtiva resulta em crises de confiança dos indivíduos em relação ao seu meio social e natural. Este fato é ilustrado pelos medos crescentes dos indivíduos com os riscos potenciais de processos de produção modernos sobre a saúde e bem-estar. Assim, tanto a distância das fontes produtoras quanto o desconhecimento dos processos produtivos privam o consumidor da possibilidade de avaliação autônoma sobre a qualidade e o risco daquilo que consome.

\section{ESTRATÉGIAS PARA ESTÍMULO DO USO DE BIOSSÓLIDOS}

A falta de informações sobre o biossólido e o desconhecimento de suas características pode apresentar-se como um fator importante para a rejeição da sua utilização em solos agrícolas. Para a solução deste problema, Andreoli et al. (1997) e Zapparoli (2000), destacam algumas estratégias como: o esclarecimento de dúvidas, com o objetivo de dissipar preconceitos existentes na população; a realização de campanhas de sensibilização da importância da prática de reuso de resíduos; a existência de subsídios financeiros criados pelos governos municipal, estadual ou federal, como por exemplo: criação de linhas de financiamento, redução de impostos dos produtores rurais que adotarem a prática de reciclagem agrícola de biossólido, entre outros; a criação de cooperativas em regiões de agricultura familiar ou em pequenas propriedades; a criação de diferencial no valor dos produtos das propriedades adeptas da prática; o incentivo ao desenvolvimento 
de pesquisas relacionadas com possíveis destinações de biossólidos nas áreas de engenharias e arquitetura, etc.

A reciclagem de resíduos de tratamento dos efluentes urbanos deve ser abordada como benéfica pelo fato destes resíduos não constituírem material inútil, pois possuem características que podem melhorar um produto, criar novos compostos ou ainda servirem como substitutos de matéria-prima, reduzindo custos e aumentando benefícios (SANTOS, 2003). A avaliação da viabilidade econômica da reciclagem é uma etapa importante da implementação do processo, haja vista que a sociedade, enquanto consumidora, apropria-se dos recursos naturais e os transforma em mercadoria (SOUZA, 2002).

\section{CONSIDERAÇÕES FINAIS}

Os impactos ambientais das atividades antrópicas estão relacionados com a geração de resíduos e com o gerenciamento destes a fim de minimizar os danos potenciais. No Brasil, a coleta e o tratamento dos efluentes urbanos é uma realidade de apenas parte da população e, ainda assim, a geração de resíduos nas Estações de Tratamento de Esgoto representa uma questão ambiental importante.

O reaproveitamento de resíduos é uma prática importante no que diz respeito às atitudes ambientalmente sustentáveis. A reciclagem agrícola de biossólidos, enquanto complemento nutricional da adubação química e agente de melhoramento das características do solo (aumento da disponibilidade de nutrientes), é uma alternativa de destinação final do lodo resultante do tratamento de efluentes. O gerenciamento do lodo produzido representa entre 20 e $60 \%$ do custo de operação de uma ETE e tem o objetivo de diminuir a pressão dos centros urbanos sobre o ambiente.

O principal impasse na aceitação popular do uso de biossólidos na agricultura encontra-se na falta de informação sobre os resíduos e suas consequências sobre $\mathrm{o}$ ambiente e a saúde humana. A realização de palestras, cursos e divulgação por parte das empresas pode contribuir para a dissolução do preconceito que existe com relação às propriedades do biossólido, entre elas, a de que este tem características próximas às dos dejetos humanos. Além disso, estudos sobre a viabilidade econômica da reciclagem agrícola dos biossólidos devem ser mais frequentes e expostos à população, pois a aceitação por parte dos agricultores está ligada à relação custo/benefício desta prática.

As pesquisas sobre cultivos agrícolas em solos tratados com biossólidos demonstram que a reciclagem destes resíduos tem benefícios nutricionais e não causam contaminação dos solos ou dos vegetais. Tais pesquisas poderiam ampliar-se 
e abranger estudos sobre o nível de conhecimento dos produtores rurais e da população local sobre o lodo e o aproveitamento de resíduos na agricultura, a fim de dar embasamento às práticas de educação ambiental necessárias.

Considerando-se que o biossólido, enquanto objeto de estudo, pode ser abordado sob os aspectos ambiental, econômico e social, o presente trabalho pode servir como base para pesquisas futuras de tendências de mercado ambientalmente interessantes para a utilização agrícola de resíduos.

Agradecimentos: R.D. Pereira agradece 0 apoio obtido através da concessão da Taxa PROSUP-CAPES (Coordenadoria de Aperfeiçoamento e Pessoal de Nível Superior) - Ministério da Educação, Brasil.

\section{REFERÊNCIAS}

ANDREOLI, C. V. et al. Proposição de plano de monitoramento da reciclagem agrícola do lodo de esgoto no Estado do Paraná. In: CONGRESSO BRASILEIRO DE ENGENHARIA SANITÁRIA E AMBIENTAL. 19., 1997, Foz do Iguaçu. Anais eletrônico... Foz do Iguaçu: [s.n.], 1997. Disponível em:

$<$ http://www.bvsde.paho.org/bvsacd/abes97/ plano.pdf>. Acesso em: 20 jun. 2012.

ANDREOLI, C. V. Lodo de esgotos: tratamento e disposição final. Belo Horizonte:

Departamento de Engenharia Sanitária e Ambiental - UFMG, Companhia de Saneamento do Paraná, 2001.
BEECHER, N.; B. Connell; E. Epstein; J. Filtz; N. Goldstein; M. Lono. Biosolid and residuals Public perception of biosolids recycling: developing public participation and earning trust. Water Environment Research Foundation, Alexandria, VA. 2004.

BEECHER, N. et al. Risk perception, risk communication, and stakeholder involvement for biosolids management and research. J.

Environ. Qual., v. 34, p. 122-128, 2005.

BETTIOL, W.; CARVALHO, P. C. T. Utilização de lodo de esgoto primário e fertilizante organomineral IPT na cultura do milho. Fertilizantes, v. 44, p. 14-15, 1982.

BETTIOL, W.; CAMARGO, O. A. A disposição do lodo de esgoto em solo agrícola. In: EMBRAPA MEIO AMBIENTE, Lodo de esgoto: impactos ambientais na agricultura. Jaguariúna: Embrapa, 2006.

BOEIRA, R.C.; SOUZA, M. D. Estoques de carbono orgânico e de nitrogênio, $\mathrm{pH}$ e densidade de um latossolo após três aplicações de lodos de esgoto. R. Bras. Ci. Solo, v. 31, p. 581-590, 2007. http://dx.doi.org/10.1590/S010006832007000300018

BRAGA, B. et al. Introdução à engenharia ambiental. 2 ed. São Paulo: Pearson Prentice Hall, 2005.

BRASIL. Congresso Nacional. Lei no 11.445 de 05 de janeiro de 2007. Estabelece diretrizes para o saneamento básico, altera as Leis $\mathrm{n}$ ㅇ 6.766 de 19 de dezembro de 1979, 8.036, de 11 de maio de 1990, 8.666, de 21 de junho de 1993, 8.987, de 13 de fevereiro de 1995; revoga a Lei no 6.528, de 11 de maio de 1978; e dá outras providências. Disponível em: <http://www.planalto.gov.br/ccivil 03/ ato20 07-2010/2007/lei/l11445.htm>. Acesso em: 15 jul 2012.

BRASIL. Pesquisa Nacional de Saneamento Básico. Instituto Brasileiro de Geografia e Estatística - IBGE. Rio de Janeiro, 2010. 
CHIBA, M. K. Uso de lodo de esgoto na canade-açúcar como fonte de nitrogênio e fósforo: parâmetros de fertilidade do solo, nutrição da planta e rendimentos da cultura. 2005. Tese (Doutorado). Escola Superior de Agricultura Luiz de Queiroz, Universidade de São Paulo, Piracicaba.

CORREA, J. C. et al. Aplicação superficial de escória, lama cal, lodos de esgoto e calcário na cultura da soja. Pesq. Agropec. Bras., v. 43, n. 9, p. 1209-1219, 2008. http://dx.doi.org/10.1590/S0100$\underline{204 \times 2008000900016}$

GUEDES, M. C. Ciclagem de nutrientes após aplicação de lodo de esgoto (biossólido) sobre latossolo cultivado com Eucalyptus grandis. 2005. Tese (Doutorado). Escola Superior de Agricultura Luiz de Queiroz, Universidade de São Paulo, Piracicaba.

GUEDES, M. C. et al. Propriedades químicas do solo e nutrição do eucalipto em função da aplicação de lodo de esgoto. R. Bras. Ci. Solo, v. 31, p. 267-280, 2006.

JACOBI, P. R. Educação ambiental: o desafio da construção de um pensamento crítico, complexo e reflexivo. Educação e Pesquisa, São Paulo, v. 31, n. 2, p. 233-250, 2005.

LIMA, G. F. C.; PORTILHO, F. Sociologia ambiental: formação, dilemas e perspectivas. Revista Teoria \& Sociedade, Belo Horizonte, n. 7, p. 241-276,2001

LOBO, T. F.; GRASSI FILHO, H. Níveis de lodo de esgoto na produtividade do girassol. J. Soil Sc. Plant Nutr., v. 7, n. 3, p. 16-25, 2007.

NASCIMENTO C. W. A. et al. Alterações químicas em solos e crescimento de milho e feijoeiro após aplicação de lodo de esgoto. $\mathbf{R}$. Bras. Ci. Solo, v. 28, p. 385-392, 2004. http://dx.doi.org/10.1590/S0100$\underline{06832004000200017}$
NOGUEIRA, T. A. R. et al. Metais pesados e patógenos em milho e feijão caupi consorciados adubados com lodo de esgoto. Rev. Bras. de Eng. Agric. e Amb., Campina Grande, v. 11, n. 3, p. 331-338, 2007.

NUVOLARI, A. Inertização de lodo de esgoto em tijolos cerâmicos maciços: aspectos tecnológicos e ambientais. 2002. Tese (Doutorado). Faculdade de Engenharia Civil, Arquitetura e Urbanismo, Universidade Estadual de Campinas, Campinas.

OLIVEIRA, F. C. et al. Lodo de esgoto como fonte de macronutrientes para a cultura do sorgo granífero. Sci. Agric., Piracicaba, v. 52, n. 2, p. 360-367, 1995.

OMS - Organização Mundial de Saúde. Situação do Saneamento no Brasil. Disponível em:

<http://www.tratabrasil.org.br/detalhe.php?s ecao=20>. Acesso em: 15 jul. 2012.

PIRES, A. M. M.; MATTIAZZO, M. E. Avaliação da viabilidade do uso de resíduos na agricultura. EMBRAPA, Circular Técnica. Jaguariúna, 2008.

PORTILHO, F. Consumo sustentável: limites e possibilidades de ambientalização e politização das práticas de consumo. FGV, Cadernos Ebape, Edição temática, 2005.

RANGEL, O. J. P. et al. Efeito de aplicações de lodos de esgoto sobre os teores de metais pesados em folhas e grãos de milho. R. Bras. Ci. Solo, Viçosa, v. 30, n. 3, 2006. Disponível em:

<http://www.scielo.br/pdf/rbcs/v30n3/31223. pdf>. Acesso em: 20 jun. 2012.

SANTOS, A. D. Estudo das possibilidades de reciclagem dos resíduos de tratamento de esgoto da região metropolitana de São Paulo. 2003. Dissertação (Mestrado). Escola Politécnica, Universidade de São Paulo, São Paulo. 
SILVA, F. C. et al. Cana de açúcar cultivada em solo adubado com lodo de esgoto: nutrientes, metais pesados e produtividade. Pesq.

Agropec. Bras., v. 33, p. 1-8, 1998.

SILVA, F. C. et al. Efeito de lodo de esgoto na fertilidade de um Argissolo Vermelho-

Amarelo cultivado com cana-de-açúcar. Pesq.

Agropec. Bras., v. 36, n. 5, p. 831-840, 2001.

http://dx.doi.org/10.1590/S0100-

$\underline{204 \times 2001000500014}$

SIMONETE, M. A. et al. Efeito do lodo de esgoto em um Argissolo e no crescimento e nutrição de milho. Pesq. Agropec. Bras., Brasília, v. 38, n. 10, p. 1187-1195, 2003.

SLOVIC, P. Trust, emotion, sex, politics, and science: surveying the risk-assessment battlefield. Risk Anal., v. 19, p. 689-701, 1999.

SOUZA, M. S. Meio ambiente urbano e saneamento básico. Mercator - Revista de Geografia da UFC, ano 1, n. 1, 2002.

VIEIRA, R. F. et al. Disponibilidade de nutrientes no solo, qualidade de grãos e produtividade da soja em solo adubado com lodo de esgoto. Pesq. Agropec. Bras., v. 40, n. 9, p. 919-926, 2005. http://dx.doi.org/10.1590/S0100$\underline{204 \times 2005000900012}$

VON SPERLING, M. Introdução à qualidade das águas e ao tratamento de esgotos. 3. ed. Belo Horizonte: Departamento de Engenharia Sanitária e Ambiental, Universidade Federal de Minas Gerais, 2005.

Recebido para publicação em 27/08/2013

Revisado em 13/09/2013

Aceito em 16/09/2013 